\title{
TRANSESTERIFICAÇÃO ENZIMÁTICA DE SINGLE CELL OIL (SCO) DE Mucor circinelloides PARA A PRODUÇÃO DE BIODIESEL
}

\author{
A. K. F. CARVALHO ${ }^{1}$, J. D. RIVALDI ${ }^{1}$, P. C. M. DA RÓS ${ }^{1}$, H. F. de CASTRO ${ }^{1}$ \\ ${ }^{1}$ Escola de Engenharia de Lorena - USP, Departamento de Engenharia Química \\ E-mail para contato: anacarvalho@usp.br
}

\begin{abstract}
RESUMO - Entre os maiores produtores de lipídios encontra-se o fungo Mucor circillenoides que apresenta lipídios ricos em ácidos graxos poli-insaturados, de alta demanda comercial capazes de atuar como matéria-prima alternativa na produção de biodiesel. Deste modo, o objetivo desse trabalho foi estudar a produção de biodiesel a partir de lipídio produzido por Mucor circinelloides URM 4182. O crescimento celular e a acumulação de lipídios foram investigados em meio contendo glicose como fonte principal de carbono. A extração do lipídio da biomassa foi realizada utilizando etanol como solvente sob irradiação de microondas. O óleo microbiano obtido foi submetido à reação de etanólise utilizando lipase de Candida antarctica (Novozym ${ }^{\circledR}$ 435) como catalisador. As análises de RMN ${ }^{1} \mathrm{H}$ e CLAE confirmaram a conversão de $93,2 \%$ do óleo em ésteres de etila e dos teores de mono e diglicerídeos $(4,2$ e $2,6 \% \mathrm{~m} / \mathrm{m}$, respectivamente).
\end{abstract}

\section{INTRODUÇÃO}

Existe um crescente interesse na busca de novas matérias-primas oleaginosas de baixo custo para a produção de biodiesel, especialmente aquelas destinadas à alimentação (Leesing; Baojungharn, 2011). Uma alternativa que tem recebido destaque corresponde ao uso de lipídios microbianos, possíveis de ser utilizados como matéria-prima para este fim. Comparado com óleos vegetais e gordura animal, a produção de óleo microbiano não é afetada pela localização ou clima, devido a que sua produção pode ser conduzida em biorreatores de elevado volume por unidade de superfície em condições controladas (Perez-Garcia et.al., 2011).

Desta maneira, a produção de biodiesel utilizando single cell oil (SCOs) tem recebido importância recentemente por ser uma potencial fonte de energia renovável e compatível com o conceito das biorrefinarias (Vongsangnak et al., 2013). O termo single cell oil foi cunhado com a intenção de denominar principalmente os triglicerídeos de microrganismos, similares aos encontrados em óleos e gorduras provenientes de fontes animais e vegetais. Os microrganismos capazes de produzir e acumular mais de $20 \%$ de sua biomassa em lipídios são denominados oleaginosos que podem pertencer ao grupo das bactérias, leveduras, fungos e algas (Economou et al., 2011).

Dentre os micro-organismos produtores de lipídios, o gênero Mucor tem grande importância biotecnológica por ser uma fonte de carotenoides e lipídios, devido ao acumulo de altos níveis desses compostos em seu micélio. Atualmente essa propriedade tem sido muito estudada, uma vez que pode ser extraído facilmente monoésteres da biomassa, o que torna essa espécie uma fonte 
alternativa de óleo para a produção de biodiesel. Entre os maiores produtores de lipídios encontrase a espécie de fungo Mucor circillenoides que apresenta lipídios ricos em ácidos graxos poliinsaturado, principalmente ácido- $\gamma$-linolénico (GLA, 18:3, n-6) de alta demanda comercial, podendo ser utilizado como matéria-prima alternativa na produção de biodiesel (Vongsangnak et al., 2013) .

Em trabalhos anteriormente desenvolvidos verificou-se que o fungo Mucor circinelloides URM 4182 é um potente produtor de enzimas, particularmente lipases intracelulares (Andrade et al., 2012), desta forma, o objetivo do presente trabalho foi explorar a capacidade desta particular linhagem de fungo em produzir lipídios (single cell oil) para posterior utilização na síntese de biodiesel.

\section{MATERIAIS E MÉTODOS}

\subsection{Micro-organismo e Manutenção da Cepa}

No presente trabalho foi avaliada a capacidade produtora de lipídeos pela estirpe Mucor circillenoides $f$. griseo-cyanus URM-4182 adquirida da micoteca da Universidade Federal de Pernambuco (URM-UFPE). Os esporos foram mantidos em ágar PDA (Potato-Dextrose Agar) a $4^{\circ} \mathrm{C}$.

\subsection{Cultivo da Biomassa}

Os cultivos foram realizados em frascos Erlenmeyer de $250 \mathrm{~mL}$ contendo $100 \mathrm{~mL}$ de meio constituído de: glicose, $20 \mathrm{~g} / \mathrm{L}$; sulfato de amônia, 1,5 g/L; ácido glutâmico, 1,5 g/L; acido nicotínico, $1 \mathrm{mg} / \mathrm{L}$; tiamina, $1 \mathrm{mg} / \mathrm{L}$ e extrato de levedura, $0,5 \mathrm{~g} / \mathrm{L} . \mathrm{O} \mathrm{pH}$ foi ajustado para 4,5 mediante adição de $\mathrm{NaOH}(1,0 \mathrm{M})$. Os frascos foram inoculados com uma suspensão $1.10^{6}$ esporos $/ \mathrm{mL}$ de meio e incubados sob agitação $(250 \mathrm{rpm})$ a $26{ }^{\circ} \mathrm{C}$ por $96 \mathrm{~h}$. Os experimentos foram conduzidos em duplicata.

\subsection{Extração e Recuperação de Lipídios}

A extração com etanol foi realizada utilizando 2,0 g de biomassa Mucor circillenoides (90\% umidade) suspensa em $25 \mathrm{~mL}$ de etanol (95\%) e submetida a tratamento térmico em reator de micro-ondas (Modelo CEM Discover/University-Wave, Cem Corporation) consistindo de uma câmara cilíndrica interna de $750 \mathrm{~mm}^{3}$ com agitador magnético e controle de temperatura por fluxo de ar comprimido. A temperatura dentro da câmara foi controlada mediante variação automática da potência de micro-ondas sendo a máxima de $300 \mathrm{~W}$. Os lipídios $(\%, \mathrm{~m} / \mathrm{m})$ foram obtidos mediante um tratamento extrativo de $30 \mathrm{~min}$ na temperatura de $60{ }^{\circ} \mathrm{C}$. O óleo obtido da biomassa do Mucor circillenoides foi caracterizado quanto aos índices de acidez, iodo e saponificação, adotando normas estabelecidas pela AOCS (2004).

\subsection{Biocatalisador}

O biocatalisador utilizado foi a lipase microbiana de Candida antactica Lipase B imobilizada em suporte acrílico (Novozym $\left.{ }^{\circledR} 435\right)$ adquirida da Sigma-Aldrich. 


\subsection{Síntese de Biodiesel}

As reações foram efetuadas em reatores de vidro cilíndrico encamisados, acoplados com condensador de refluxo utilizando 20 gramas de meio reacional na razão molar óleo/etanol de $1: 12 ; 10 \%$ de biocatalisador em relação à massa de meio reacional $(2,0 \mathrm{~g})$ sob agitação magnética de $150 \mathrm{rpm}$ a $60^{\circ} \mathrm{C}$ por um período máximo de $72 \mathrm{~h}$.

\subsection{Análise de Formação de Ésteres de Etila}

As amostras purificadas foram analisadas quanto ao teor de ésteres de etila tomando por base os dados gerados por espectroscopia de ressonância magnética nuclear $\left(\mathrm{RMN}^{1} \mathrm{H}\right)$ utilizando a equação validada por Paiva et al., (2013) e quanto aos teores de monoglicerídeos e diglicerídos por cromatografia líquida de alta eficiência (CLAE).

\section{RESULTADOS E DISCUSSÃO}

\subsection{Acumulação e Extração de Lipídios}

Após o cultivo do Mucor circinelloides URM 4182 conforme descrito na seção 2.1, a biomassa produzida foi submetida ao processo de extração de lipídios utilizando etanol como solvente e micro-ondas em três ciclos de 30 mintuos a $60^{\circ} \mathrm{C}$. Em $96 \mathrm{~h}$ de cultivo o Mucor circinelloides URM 4182 produziu 46,98\% m/m de lipídio em relação à sua biomassa seca. Esses resultados são similares aos relatados na literatura científica. Vicente et al., 2010, utilizaram uma linhagem de Mucor circinelloides R7B29 geneticamente modificada após a substituição do seu alelo mutante leua por um alelo de tipo selvagem. Os autores utilizaram uma mistura de solventes (água e hexano) para o processo de extração do lipídio das células e alcançaram rendimentos de total de 22,9\% de lipídio em relação ao conteúdo da biomassa seca. Vicente et al., 2009 também utilizaram uma linhagem de Mucor circinelloides modificada geneticamente e estudaram três sistemas diferentes de extração por solventes: clorofórmio: metanol, clorofórmio: metanol: água e n-hexano alcançando $15 \%$ de lipídios. O lipídio extraído de M. circinelloides URM 4182 foi caracterizado quanto ao perfil de lipídios e propriedades de interesse para controle de qualidade, incluindo índices de acidez, iodo e saponificação. O perfil e características dos lipídios produzidos por M. circinelloides URM 4182 estão apresentados na Tabela 1.

Os principais ácidos graxos encontrados nos lipídios produzidos por $M$. circinelloides URM 4182 foram o ácido palmítico $\mathrm{C}_{16: 0}(22,21 \% \mathrm{~m} / \mathrm{m})$, oleico $\mathrm{C}_{18: 1}(39,58 \% \mathrm{~m} / \mathrm{m})$ e lionoleico $\mathrm{C}_{18: 2}$ $(9,69 \% \mathrm{~m} / \mathrm{m})$. Este perfil de ácidos graxos se assemelha aos dos óleos convencionalmente utilizados para a produção de biodiesel (Carvalho et al., 2013). A elevada quantidade de ácidos graxos saturados e monoinsaturados principalmente $C_{16: 0}$ e $C_{18: 1}$ indica que esse óleo possui potencial como matéria-prima para produzir um combustível de qualidade como alternativa ao diesel convencional. Também, foi observado um teor considerável do ácido $\gamma$-linolênico $\mathrm{C}_{18:} 3$ $(10,76 \% \mathrm{~m} / \mathrm{m})$ que tem relevante importância nas indústrias farmacêuticas e de alimentos. Neste estudo, verificou-se que a estirpe de $M$. circinelloides URM 4182 produz elevada concentração de single cell oils (SCO), e portanto, possui potencial para ser utilizado como matéria-prima na produção de biodiesel. 
Tabela 1 - Propriedades físico-químicas e composição em ácidos graxos do óleo das células de Mucor circinelloides URM 4182

\begin{tabular}{|c|c|}
\hline Propriedades & \\
\hline Índice de acidez & $38 \mathrm{mg} \mathrm{KOH} / \mathrm{g}$ óleo \\
\hline Índice de saponificação & 203 mg KOH/g óleo \\
\hline Índice de iodo & $85 \mathrm{~g} \mathrm{I}_{2} / 100 \mathrm{~g}$ óleo \\
\hline Composição em ácidos graxos & $(\% \mathbf{m} / \mathbf{m})$ \\
\hline Palmítico $\left(\mathrm{C}_{16}\right)$ & 22,21 \\
\hline Esteárico $\left(\mathrm{C}_{18}\right)$ & 7,77 \\
\hline Oleico $\left(\mathrm{C}_{18: 1}\right)$ & 39,58 \\
\hline Linoleico $\left(\mathrm{C}_{18: 2}\right)$ & 9,69 \\
\hline Gama linolênico GLA $\left(\mathrm{C}_{18: 3}\right)$ & 10,81 \\
\hline Outros & 9,94 \\
\hline
\end{tabular}

\subsection{Transesterificação do Óleo de Mucor circinelloides}

O óleo obtido das células de $M$. circinelloides URM 4182 foi submetido à transesterificação utilizando etanol como agente acilante e lipase de Candida antarctica (Novozym ${ }^{\circledR}$ 435) como catalisador. As reações foram conduzidas em duplicata por um período máximo de $72 \mathrm{~h}$. Ambas as reações atingiram elevado rendimento $(93,0 \% \mathrm{~m} / \mathrm{m} \pm 0,5)$. O elevado rendimento alcançado foi confirmado pela técnica de Ressonância Magnética Nuclear Protônica (Figura 2), que mostrou a elevada conversão do lipídio microbiano em ésteres etílicos, uma vez que o espectro apresentou o quarteto em 4,1 ppm referente ao desdobramento do pico correspondente ao hidrogênio metilênico presente na estrutura dos ésteres etílicos (Paiva et al. 2013). Este valor também foi confirmado pela técnica de cromatografia líquida de alta eficiência (CLAE) que quantificou os teores de mono-, di- e triglicerídeos.

No produto obtido a partir da etanólise do lipídio de $M$. circinelloides URM 4182, os teores de monoglicerídeos $(4,2 \%)$ e diglicerídeos $(2.8 \%)$ obtidos foram superiores aos limites mínimos estabelecidos pela ANP (2014) da ordem 0,80 e $0,20 \% \mathrm{~m} / \mathrm{m}$, respectivamente. Geralmente, a presença de glicerídeos que não reagiram, reduz a qualidade do produto final, uma vez que estes compostos aumentam a turbidez e a viscosidade do produto. Entretanto, a baixa concentração destes glicerídeos residuais e a ausência de triglicerídeos no biodiesel a partir do óleo de $M$. circinelloides URM 4182 mostraram a eficiência da conversão dos triglicerídeos em ésteres etílicos promovida pela lipase imobilizada. 


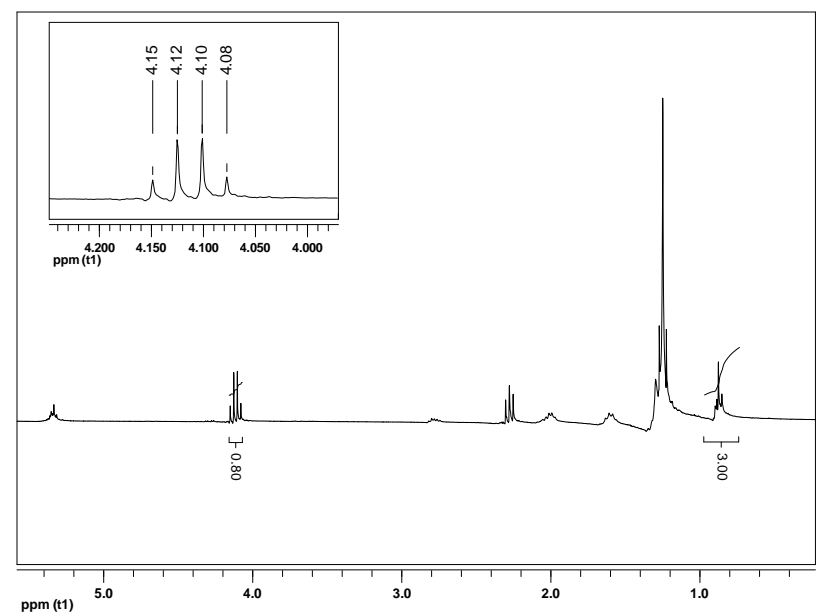

Figura 2 - Espectro de RMN ${ }^{1} \mathrm{H}$ integrado de biodiesel obtido a partir da etanólise do óleo de $M$. circinelloides URM 4182 mediada pela Novozym ${ }^{\circledR} 435$

\section{CONCLUSÃO}

No presente estudo, o óleo microbiano de $M$. circinelloides URM 4182 foi analisado quanto ao seu potencial como matéria-prima para produção de biodiesel. O rendimento total de óleo alcançado na extração foi de 46,98\% da biomassa seca após 96 h de cultivo. A extração assistida por micro-ondas utilizando etanol como solvente extrator mostrou ser um método rápido e renovável para a recuperação lipídica da biomassa de fungos. O perfil lipídico de $M$. circinelloides URM 4182 apresentou concentração elevada de ácidos graxos saturados e monoinsaturados, predominantemente $\mathrm{C}_{16}$ e $\mathrm{C}_{18: 1}$, cujo conteúdo e propriedades são semelhantes a alguns óleos vegetais normalmente utilizados para a produção de biodiesel. O conjunto de dados obtidos mostrou que a transesterificação enzimática do lipídio de $M$. circinelloides URM 4182 com etanol produziu elevado teor de ésteres de etila $(93,0 \pm 0,5 \%)$ sugerindo a potencialidade do dessas células como fonte de matéria-prima alternativa para a produção de biodiesel.

\section{REFERENCIAS}

ANDRADE, G. S. S.; FREITAS, L.; OLIVEIRA, P. C.; DE CASTRO, H. F. Screening immobilization and utilization of whole cell biocatalyst to mediate the ethanolysis of babassu oil. J. Mol. Catal. B: Enzym., v. 84, p. 183-188, 2012.

ANP. Disponível em http://www.anp.gov.br/?g=60467\&m=\&t1=\&t2=\&t3=\&t4=\&ar=\&os=\&c achebust $=1382034774841$. Acesso em 5 de abril de 2014.

AOCS. American Oil Chemists' Society Official Methods and Recommended Practices of the AOCS. $5^{\text {th }}$ Ed. AOCS Press. (2004).

CARVALHO, A.K.F.; DA RÓS, P.C.M.; TEIXEIRA, L.F.; ANDRADE, G.S.S., ZANIN, G.M.; CASTRO, H.F. Assessing the potential of non-edible oils and residual fat to be used as a feedstock source in the enzymatic ethanolysis reaction. Ind. Crops Prod., v.50, p.485 - 493, 
2013.

ECONOMOU, C. N.; VASILIADOU, I. A.; AGGELIS, G.; PAVLOU, S.; VAYENAS, D. V. Modeling of oleaginous fungal biofilm developed on semi-solid media. Bioresour. Technol., v. 102, p. 9697-9704, 2011.

LEESING, R. AND BAOJUNGHARN, R. Microbial oil production by isolated oleaginous yeast Torulaspora globosa YU5/2. Eng. and Technol., v. 5, p. 04-23, 2011.

PAIVA, E. J. M.; DA SILVA, M. L. C. P.; BARBOZA, J. C. S.; OLIVEIRA, P. C.; DE CASTRO, H. F.; GIORDANI, D. S. Non-edible babassu oil as a new source for energy production - a feasibility transesterification survey assisted by ultrasound, Ultrason Sonochem., v. 20, p. 833-838, 2013.

PEREZ-GARCIA, O.; ESCALANTE, F.M.E.; BASHAN, L.E.; BASHAN, Y. Heterotrophic cultures of microalgae: Metabolism and potential products. Water Res., v. 45, p.11-36, 2011.

VICENTE, G.; BAUTISTA, L. F.; GUTIERREZ, F. J.; RODRIGUEZ, R.; MARTINEZ, V.; RODRIGUEZ-FROMETA, R. A.; RUIZ-VAZQUEZ, R. M.; TORRES-MARTINEZ, S.; GARRE, V. Direct transformation of fungal biomass from submerged cultures into biodiesel. Energy \& Fuels, v. 24, p. 3173-3178, 2010.

VICENTE, G.; BAUTISTA, L.F.; RODRÍGUEZ, R.; GUTIERREZ, F.J.; SADABA, I.; RUIZVÁZQUEZ, R.M.; TORRES-MARTÍNEZ, S.; GARRE, V. Biodiesel production from biomass of an oleaginous fungus. Biochem. Eng. J., v.48, p.22 - 27, 2009.

VONGSANGNAK, W.; RUENWAI, R.; TANG, X.; HU, X.; ZHANG, H.; SHEN, B.; SONG, Y.; LAOTENG, K. Genome-scale analysis of the metabolic networks of oleaginous Zygomycete fungi. Gene, v. 521, p. 180-190, 2013. 